\title{
Pollutant target setting for the Great Barrier Reef: Using the eReefs framework
}

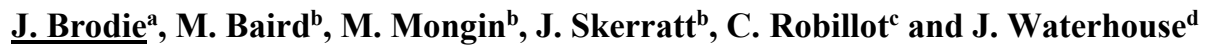 \\ a. ARC Centre of Excellence for Coral Reef Studies, James Cook University, Townsville. b. CSIRO Oceans \\ and Atmosphere, Hobart. c. HeadStart Development Pty Ltd, Brisbane. d. Centre for Tropical Water and \\ Aquatic Ecosystem Research (TropWATER), James Cook University, Townsville.
} Email: jon.brodie@jcu.edu.au

\begin{abstract}
Loads of fine sediment, nitrogen and phosphorus from the 35 major basins of the Great Barrier Reef (GBR) catchment have increased greatly over the last 150 years associated with catchment development for agriculture and urban uses. These increased loads have caused a range of effects in the GBR resulting in loss of coral and seagrass. Major effects include the promotion of increased populations of the coral predator - the crown of thorns starfish via increased nutrient availability, now a major cause of coral mortality on the GBR. A second major effect associated with increased fine sediment and nutrient loads is an increase in GBR innershelf turbidity and a subsequent reduction of light for coral and seagrass photosynthesis. Currently coral cover on the GBR is in a state of severe decline associated with these water quality effects and the increasing effects of climate change.
\end{abstract}

The water quality management plan for the GBR - Reef Plan, requires targets to be set to reduce basin pollutant loads so that marine and coastal ecosystems can be maintained in a satisfactory state. In the past targets were set for the whole of the GBR but it is now recognized that targets at the individual basin scale are required to guide management and account for the differing river plume footprints and spatial distributions of marine ecosystems along the GBR. Now as part of the Reef 2050 Water Quality Improvement Plan 2017-2022, targets for fine suspended sediment (FSS), dissolved inorganic nitrogen (DIN), particulate nitrogen (PN) and particulate phosphorus (PP) are to be set for the 35 basins to be achieved by 2025 . The targets are designed such that an ecological endpoint is reached in the GBR, which represents a satisfactory ecological condition.

Over the last 4 years CSIRO and partners have developed the eReefs marine modelling framework. The eReefs regional and relocatable models include hydrodynamic, sediment, wave and biogeochemistry models for the GBR ecosystem. The numerical models are capable of simulating and predicting the hydrodynamic state, sediment transport, water quality and basal ecology of the Great Barrier Reef lagoon and reef matrix and hence model the transport and fate of waterborne material, whether of oceanic or terrestrial origin, and its impact on GBR water quality. eReefs is now being used to help set the basin scale targets.

eReefs has included 17 of the GBR basins in the modelling carried out in 2016. Targets for the other 18 basins were estimated using other models and techniques. The eReefs modelling used the $4 \mathrm{~km}$ resolution version, four years of simulation $(2011$ - 2014) with loads from the Source Catchments model. The final endpoint criteria chosen for the estimation of targets such that specific ecological outcomes were included in the modelling were:

1. Improved coral diversity versus macroalgae. Reducing DIN loads leads to an increase in coral diversity and a reduction in macroalgae abundance. Meeting a threshold Chlorophyll a (Chl-a) concentration is used as a proxy for nutrient status. The criteria is: Chl-a $<0.45 \mu \mathrm{g} \mathrm{L}^{-1}$, all years, all waters within river footprints.

2. Improved seagrass "health". Reducing FSS loads leads to reduced turbidity throughout the year and improved light availability in shallow areas $(<10 \mathrm{~m})$ which is a key driver of seagrass abundance. The underwater light field is a reasonably intrinsically-predictable phenomena. As the major human impact on seagrass health in GBR coastal regions is reduced light, it was considered better to directly consider bottom light than other possible criteria such as seagrass biomass. The criteria is: PAR-integrated light $>6 \mathrm{~mol} / \mathrm{m}^{2} / \mathrm{day}$ for seagrass, all years, $<10 \mathrm{~m}$, all waters within river footprints - the "chronic" case.

Using scenarios that reduced fine sediment and DIN (and PN and PP in proportion with the FSS), in steps from each of the modelled basins, estimates of the loads required to meet the ecological endpoints were derived. Examples of the results include for the Tully Basin a reduction of $20 \%$ of the current anthropogenic fine sediment load and a reduction of $50 \%$ of the current anthropogenic DIN load are required by 2025.

Keywords:

Great Barrier Reef, pollutant load reduction targets, ecosystem health 
Brodie et al., Pollutant target setting for the Great Barrier Reef: Using the eReefs framework

\section{INTRODUCTION}

River discharge of fine sediment and nutrients to the Great Barrier Reef World Heritage Area (GBRWHA) has increased substantially since European settlement, with published estimated increases of up to 3 - 6-fold in loads of suspended sediment, 2 - 6-fold for nitrogen loads, and 3 - 9-fold for phosphorus loads depending on the individual river (Kroon et al. 2012; Waters et al. 2014). The main source of excess nutrients and fine sediments is agricultural land use (Waterhouse et al. 2012) (Figure 1), with increased loads of (i) fine sediment and particulate nutrients primarily derived from erosion in rangeland grazing and cropping lands; and (ii) dissolved inorganic nutrients, particularly nitrogen, associated with fertiliser applications in cropping land uses such as sugarcane and horticulture.

These increased loads of fine sediment and nutrients are considered a major contributor to the current state of degradation of the Great Barrier Reef (GBR) (Brodie and Waterhouse 2012; Brodie and Pearson 2016; De'ath et al. 2010; Hughes et al. 2015) including severe loss of coral cover (De'ath et al. 2012), extensive seagrass loss (Petus et al. 2014; Coles et al. 2015) and consequent reduced populations of megafauna including dugongs. The recent bleaching episodes on the GBR (Hughes et al. 2017a,b) show the critical role climate change is now having in driving coral mortality and the ever more urgent need to reduce pollutant loads to provide resilience in the face of such climate change effects.

In 2009, as part of the Great Barrier Reef Water Quality Protection Plan (Reef Plan 2009), end-of-system (for all GBR basins together) load targets for fine sediment and nutrients were established for the entire Great Barrier Reef (Queensland and Australian Governments, 2009). The targets were set on the basis of what could be attained through achievable agricultural "best management practices" on the Great Barrier Reef Catchment (GBRC) (Brodie et al. 2012). The targets were however not set on the basis of ecological end points for GBR ecosystems although attempts to design targets of this type have been made (e.g. Brodie et al. 2009; Kroon 2012; Wooldridge et al. 2015). Revised targets were developed in 2013 to replace the 2009 targets as part of the Reef Plan update (Queensland and Australian Governments, 2013), but these are also only for the entire GBR and are not designed to reach an ecological end point.

Reef Plan is being updated in 2017 and as part of the update it is required that targets be established to reduce basin pollutant loads such that marine and coastal ecosystems can be maintained in a satisfactory state. In the past, targets were set for the whole of the GBR, but it is now recognized that targets at the individual basin scale are required to guide management and account for the differing spatial patterns of ecosystems along the GBR. Now, as part of the 2017 Reef Plan (Queensland and Australian governments, 2017), targets for fine suspended sediment (FSS), dissolved inorganic nitrogen (DIN), particulate nitrogen (PN) and particulate phosphorus (PP) are to be set for the 35 basins to be achieved by 2025 . The targets are to be designed such that an ecological endpoint is reached in the GBR, which represents a satisfactory ecological condition.

The Water Quality Guidelines for the GBR Marine Park (GBRMPA 2010) are the primary guidelines defined to support and maintain GBR ecosystem health, and were first used to conceptually link GBR water quality with pollutant load reductions at a regional scale (Kroon 2012). Since then, both regional and basin-specific targets have been developed for pollutant load reductions that will ensure that these guidelines are met. The targets developed in the current study, referred to as 'ecologically relevant targets (ERTs)', are necessary to achieve the overall original long-term Reef Plan goal "To ensure that by 2020 the quality of water entering the reef from broadscale land use has no detrimental effect on the reef's health and resilience". 


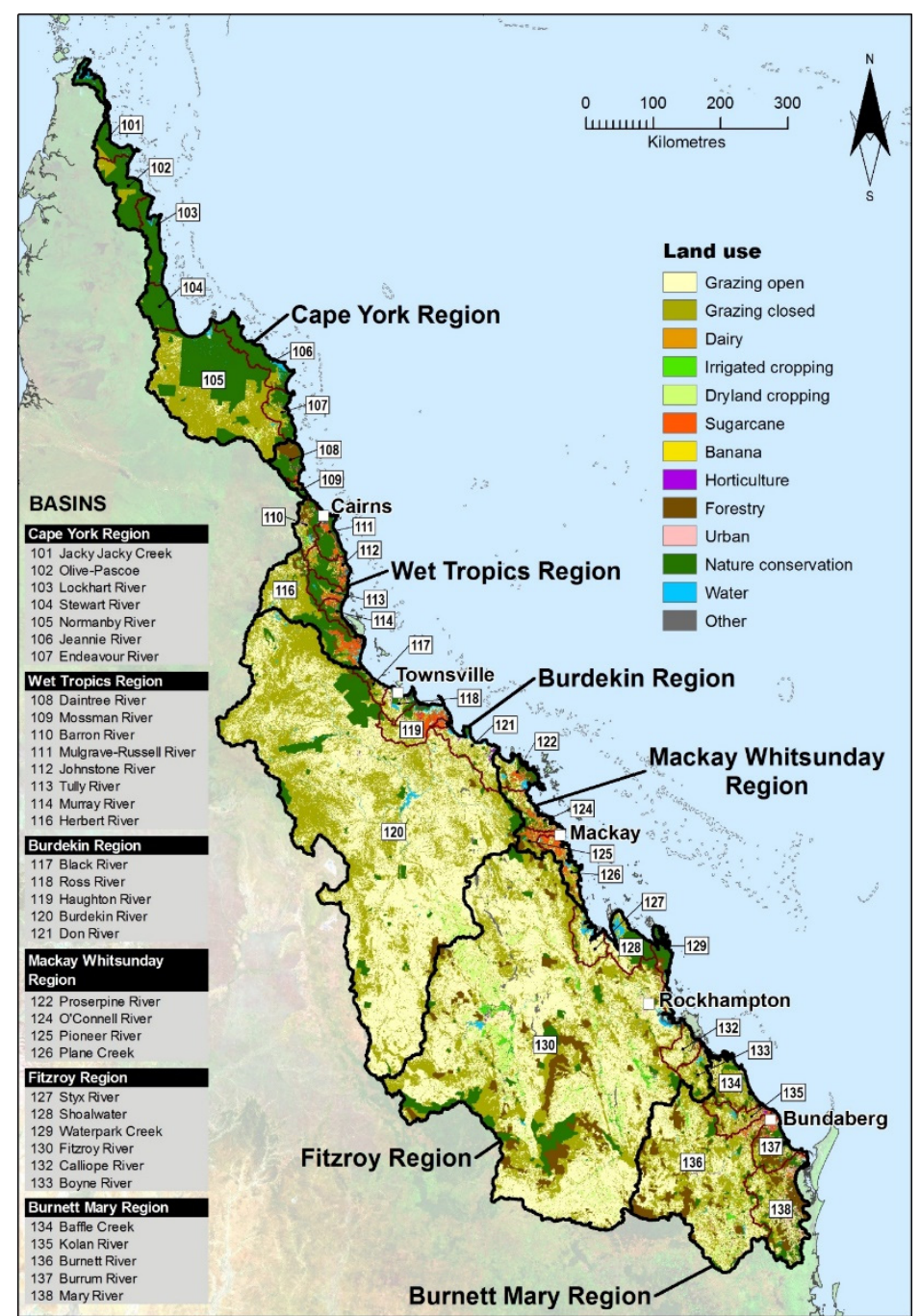

Figure 1. Boundaries of the 35 basins (as defined by the Australian Water Resources Council) and land use in the Great Barrier Reef catchment. Map data provided by DNRM.

\section{METHODOLOGY}

Since 2013 CSIRO and partners have developed the eReefs modelling framework (e.g. Baird et al. 2016). The eReefs regional and relocatable models include hydrodynamic, sediment, wave and biogeochemistry models for the GBR ecosystem. eReefs is able to deliver numerical models capable of simulating and predicting the physical hydrodynamic state, sediment transport, water quality and basal ecology of the Great Barrier Reef lagoon and reef matrix and hence model the transport and fate of waterborne material, whether of oceanic or terrestrial origin, and its impact on GBR water quality.

The eReefs model is first used to define the spatially and temporally evolving spatial extent (or footprint) of each river. The limit of the footprint is defined as the contour of $1 \%$ of river water. Secondly, within each footprint, we analyse the biogeochemical state (water quality, turbidity etc.) to determine the impact of changes in catchment loads. Using this approach, we are firstly able to restrict our analysis of the impact of catchment loads to the regions most influenced by river plumes, thus avoiding biasing our analysis through averaging regions of high river impact with regions less affected by terrestrial discharge. And secondly, and we are able to attribute water quality impacts to specific rivers, thus allowing us to develop basin-specific load targets.

The eReefs model has included 17 of the GBR basins in the modelling carried out in 2016 and this part of the target-setting process is what is included in this paper. Targets for the other 18 basins were estimated using other models and techniques not discussed here (Brodie et al. 2017). Here the $4 \mathrm{~km}$ resolution eReefs model is forced with input loads from the Source Catchments model for the years 2011-2014. The final endpoint criteria chosen for the estimation of targets were: 
Brodie et al., Pollutant target setting for the Great Barrier Reef: Using the eReefs framework

1. Improved coral diversity versus macroalgae. Reducing DIN loads leads to an increase in coral diversity and a reduction in macroalgae abundance. Meeting a threshold Chlorophyll a (Chl-a) concentration is used as a proxy for nutrient status. The criteria is: Chl-a $<0.45 \mu \mathrm{g} \mathrm{L}^{-1}$, all years, all waters within river footprints.

2. Improved seagrass "health". Reducing FSS loads leads to reduced resuspension throughout the year and improved light availability in shallow areas $(<10 \mathrm{~m})$ which is a key driver of seagrass abundance. The criteria is: Light $>6 \mathrm{~mol} / \mathrm{m}^{2} /$ day for seagrass, all years, $<10 \mathrm{~m}$, all waters within river footprints - the "chronic" case.

The reduced model skill for the Herbert and Normanby footprints (due to poor model resolution and model forcing errors respectively) has meant these regions could not be used accurately. Thus the number of basins where eReefs was used was reduced to 15: Mary, Burnett, Calliope, Boyne, Fitzroy, Pioneer, O’Connell, Don, Burdekin, Haughton, Tully, Johnstone, Russell-Mulgrave, Barron and Daintree.

Using modelled Source catchment load scenarios that reduced fine suspended sediment (FSS) and DIN and DIP (and PN and PP in step with the FSS), estimates of the loads required to meet the ecological endpoints were derived. Of this PP, we assume $90 \%$ as adsorbed phosphorus, and $10 \%$ as refractory phosphorus. This ratio generally aligns with the values that occur in the received waters as a result of the parameter values chosen in the model. Six input scenarios for river pollutant loads were used (see Table 1) in which river loads across all rivers were changed simultaneously (i.e. there is no scenario for reduction in loads in any individual river but not other rivers). All reductions were proportions applied throughout year. This means that absolute load reductions were mainly during the wet season because this is when the loads are mostly delivered. The eReefs model (at $4 \mathrm{~km}$ resolution) has been run from 2011 to 2014 using sediment and nutrient loads from two SOURCE catchment model outputs - one based on 2012-2013 catchment management practices (Baseline or scenario B) and one based on estimated pre-development catchment condition with present day water infrastructure (Pre-development or 'scenario P'). The differences in input loads between the two scenarios are the calculated anthropogenic loads.

In addition, four intermediate scenarios were run based on incremental reductions applied to estimated anthropogenic daily loads as follows:

Scenario 1. A theoretical load reduction increment applied to the anthropogenic component of $50 \%$ for nutrients and $20 \%$ for sediments (from 2009 baseline) which is equivalent to the original 2018 Reef Plan targets (Australian and Queensland Governments 2013);

Scenario 2. A theoretical load reduction increment applied to the anthropogenic component of $60 \%$ for nutrients and $30 \%$ for sediments (from 2009 baseline);

Scenario 3. A theoretical load reduction increment applied to the anthropogenic component of $70 \%$ for nutrients and $40 \%$ for sediments (from 2009 baseline); and

Scenario 4. A theoretical load reduction increment applied to the anthropogenic component of $80 \%$ for nutrients and $50 \%$ for sediments (from 2009 baseline) which is equivalent to the 2025 Reef 2050 Long Term Sustainability Plan (Reef 2050 Plan) targets (Commonwealth of Australia 2015).

Table 1. The load reduction scenarios assessed for target setting based on anthropogenic load reductions and progress to date.

\begin{tabular}{|c|c|c|c|c|c|c|}
\hline \multirow[b]{2}{*}{ Scenario } & \multicolumn{3}{|c|}{ Sediments } & \multicolumn{3}{|c|}{ Nutrients } \\
\hline & $\begin{array}{c}\text { Scenario } \\
\text { anthropogenic } \\
\text { load reduction } \\
(\%)\end{array}$ & $\begin{array}{c}\text { Progress } \\
\text { to date } \\
2013 \text { - } \\
11 \%\end{array}$ & $\begin{array}{c}\% \text { of } \\
\text { anthropogenic } \\
\text { FSS loads } \\
\text { modelled }\end{array}$ & $\begin{array}{c}\text { Scenario } \\
\text { anthropogenic } \\
\text { load reduction } \\
(\%)\end{array}$ & $\begin{array}{c}\text { Progress } \\
\text { to date } \\
2013- \\
16 \%\end{array}$ & $\begin{array}{c}\% \text { of } \\
\text { anthropogenic } \\
\text { nutrient loads } \\
\text { modelled }\end{array}$ \\
\hline Baseline & 0 & \multirow{6}{*}{11} & 0 & 0 & \multirow{6}{*}{16} & 0 \\
\hline Scenario 1 & 20 & & 10.1 & 50 & & 40.5 \\
\hline Scenario 2 & 30 & & 21.3 & 60 & & 52.4 \\
\hline Scenario 3 & 40 & & 32.6 & 70 & & 64.3 \\
\hline Scenario 4 & 50 & & 43.8 & 80 & & 76.2 \\
\hline $\begin{array}{l}\text { Pre- } \\
\text { development }\end{array}$ & 100 & & 100 & 100 & & 100 \\
\hline
\end{tabular}

To account for progress made in reducing loads through management between 2009 and 2013 the reductions made in the scenarios were adjusted to reflect this progress as shown in Table 1. 
Brodie et al., Pollutant target setting for the Great Barrier Reef: Using the eReefs framework

\section{RESULTS}

The final end-of-basin water quality target recommended for fine sediment, DIN, PN, PP for the 15 GBR basins where eReefs was the main method of estimation are shown in Table 2. Results are shown as required reductions as percentages of anthropogenic loads.

Table 2. Required anthropogenic load reductions to achieve Chl-a and bottom light ecological targets for the 15 basins modelled using eReefs as the primary method.

\begin{tabular}{|c|c|c|c|c|c|}
\hline NRM Region & Basin & $\begin{array}{l}\text { Fine sediment } \\
\text { reduction } \%\end{array}$ & $\begin{array}{c}\text { DIN reduction } \\
\%\end{array}$ & PP reduction \% & $\begin{array}{c}\text { PN } \\
\text { reduction } \\
\%\end{array}$ \\
\hline \multirow[t]{10}{*}{ Wet Tropics } & Daintree River & 0 & 0 & 0 & 0 \\
\hline & Barron River & 0 & 60 & 0 & 0 \\
\hline & $\begin{array}{l}\text { Mulgrave- } \\
\text { Russell River }\end{array}$ & 10 & 70 & 10 & 10 \\
\hline & Johnstone River & 40 & 70 & 40 & 40 \\
\hline & Tully River & 20 & 50 & 20 & 20 \\
\hline & Haughton River & 0 & 70 & 0 & 0 \\
\hline & Burdekin River & 30 & 60 & 30 & 30 \\
\hline & Don River & 30 & 0 & 30 & 30 \\
\hline & O'Connell River & 40 & 70 & 40 & 40 \\
\hline & Pioneer River & 20 & 70 & 20 & 20 \\
\hline \multirow[t]{3}{*}{ Fitzroy } & Fitzroy River & 30 & 0 & 30 & 30 \\
\hline & Calliope River & 30 & 0 & 30 & 30 \\
\hline & Boyne River & 40 & 0 & 40 & 40 \\
\hline \multirow[b]{2}{*}{ Burnett Mary } & Burnett River & 20 & 70 & 20 & 20 \\
\hline & Mary River & 20 & 50 & 20 & 20 \\
\hline
\end{tabular}

\section{DISCUSSION AND CONCLUSIONS}

This project has demonstrated the value of the application of the eReefs modelling platform and load reduction scenarios in establishing basin specific water quality targets. The caveats in the use of the eReefs model discussed below have also highlighted the importance of continued development and improvement of these methods and identified opportunities for future work. The development of basin-specific pollutant load reductions targets that are ecologically relevant is a major step forward from the 2013 Reef Plan targets and provide a strong scientific basis for more targeted management of water quality in the Great Barrier Reef and its catchments.

A number of caveats in the use of the eReefs modelling need to be given. These include:

1. We assume the river with the greatest influence on a particular location at a particular time is solely responsible for the water quality at that time. This will generally be true of suspended sediments. In some cases nutrients can spread in the plume of one river, but influence the water quality at a later time when another river has a greater influence. This is most clearly seen in the Wet Tropics rivers, with a number of rivers in close proximity, and for small rivers near large rivers, such as the Calliope and Fitzroy plumes. As the final load reduction calculations are averaged over seasons, any river mis-attribution errors are likely to cancel out.

2. Although for example the Source Catchment loads are shown for just DIN or suspended sediment, each scenario implies both a fine sediment and DIN load. Thus when the load type shown is DIN, there is still a reduction of suspended sediment. For some variables, such as Chl-a, it may be safe to assume that DIN loads drive Chl-a within the river footprint. But for other variables, such as bottom light, it is a combination of fine sediment and DIN. Thus caution should be exercised when using a single figure to determine reductions in loads. All scenarios modelled suspended sediment and nutrient reductions simultaneously. Thus coupled results needed to be disentangled to determine the most important factor driving the marine response (FSS or nutrients). We focused on the primary parameter, but can consider the secondary influence on a case by case 
Brodie et al., Pollutant target setting for the Great Barrier Reef: Using the eReefs framework

basis. Generally in this study, for DIN, we ignored the fine sediment 'matching' target and for fine sediment ignored the 'matching' DIN target.

3. It is assumed that the Source Catchments pre-development load estimates are the best currently available and are not questioned through this process.

4. Application of the eReefs $4 \mathrm{~km}$ output results in large spatial interpolations of data in some locations, particularly where there are narrow channels such as Hinchinbrook Channel. This coarse grid size is particularly limiting along the coastline, where shallow waters and resuspension events can dominate conditions, and where intertidal seagrass beds are often located. In fact, with a $4 \mathrm{~km}$ resolution, many of the shallow regions with seagrass appear either as land, or as grid cells too deep for seagrass. This limitation is likely to result in underestimates in the calculation of potential exposure of seagrass to FSS and DIN. This is also relevant to coral reefs, although there are comparably smaller areas of reefs in these near shore coastal waters.

Additionally the modelling effort and model parameterization can be improved with the following refinements:

1. Use a longer modelling period for the analysis e.g. seven years is now available rather than the four years available at the commencement of this project.

2. Improve basin water discharge estimates such that the total basin gauged and ungauged flow is used rather than the current method of estimates made from a single gauge site in each basin.

3. Include more rivers (basins) e.g. importantly the Murray, Proserpine, Plane, Burrum, Baffle, Kolan (all with significant areas of sugarcane and horticulture cultivation) and resolve the difficulties in modelling the Herbert and Normanby.

4. Use of the higher-resolution $1 \mathrm{~km}$ model.

5. Run separate scenarios for nutrient reductions and for the sediment reductions.

6. Model a greater range of scenario options, including future scenarios.

7. Improve the analysis of other endpoints for DIN e.g. crown of thorns starfish response to nutrients and changes in bleaching response in the presence of elevated nutrients, attempted in the current targets setting but not used due to insufficient confidence in the results.

\section{ACKNOWLEDGMENTS}

We acknowledge the Queensland and Australian Governments for funding this project. We would also like to thank the numerous people who reviewed and commented on the results from the fine sediment and nutrient target setting project including, in particular, Roger Shaw, John Bennett, Peter Doherty, Nyssa Henry, Carl Mitchell and Stephen Lewis.

\section{REFERENCES}

Baird, M.E., Cherukuru, N., Jones, E., Margvelashvili, N., Mongin, M., Oubelkheir, K., Ralph, P.J., Rizwi, F., Robson, B.J., Schroeder, T., Skerratt, J. (2016). Remote-sensing reflectance and true colour produced by a coupled hydrodynamic, optical, sediment, biogeochemical model of the Great Barrier Reef, Australia: Comparison with satellite data. Environmental Modelling \& Software 78, 79-96.

Brodie, J. Waterhouse, J. (2012). A critical review of environmental management of the 'not so Great' Barrier Reef. Estuarine, Coastal and Shelf Science 104-105, 1-22.

Brodie J., Pearson, R. (2016). Ecosystem health of the Great Barrier Reef: Time for effective management action based on evidence. Estuarine, Coastal and Shelf Science 183, 438-45.

Brodie, J. Lewis, S. Bainbridge, Z. Mitchell, A. Waterhouse, J. Kroon, F. (2009). Pollutant discharge management target setting for rivers in the Great Barrier Reef Catchment Area. Marine and Freshwater Research 60, 1141-1149.

Brodie, J., Baird, M., Waterhouse, J., Mongin, M., Skerratt, J., Robillot, C., Smith, R., Mann, R., Warne, M., (2017). Development of basin-specific ecologically relevant water quality targets for the Great Barrier Reef. TropWATER Report No. 17/38, James Cook University, Published by the State of Queensland, Brisbane, Australia. 68 pp. http://www.reefplan.qld.gov.au/about/assets/gbr-water-quality-targets-june2017.pdf 
Brodie et al., Pollutant target setting for the Great Barrier Reef: Using the eReefs framework

Coles, R.G., Rasheed, M.A., McKenzie, L.J., Grech, A., York, P.H., Sheaves, M., McKenna, S., Bryant, C. (2015). The Great Barrier Reef World Heritage Area seagrasses: managing this iconic Australian ecosystem resource for the future. Estuarine, Coastal and Shelf Science 153, A1-A12.

De'ath, G. Fabricius, K.E. (2010). Water quality as a regional driver of coral biodiversity and macroalgae on the Great Barrier Reef. Ecological Applications 20, 840-850.

De'ath, G. Fabricius, K.E. Sweatman, H. Puotinen, M. (2012). The 27-year decline of coral cover on the Great Barrier Reef and its causes. Proceedings of the National Academy of Sciences 190, 17995-17999.

GBRMPA 2010. Great Barrier Reef Marine Park Authority (2010). Water Quality Guidelines for the Great Barrier Reef Marine Park. Great Barrier Reef Marine Park Authority, Townsville, 99p.

Hughes, T.P., Day, J., Brodie, J. (2015). Securing the Future of the Great Barrier Reef. Nature Climate Change, $5,508-511$.

Hughes, T.P., Kerry, J.T., Álvarez-Noriega, M., Álvarez-Romero, J.G., Anderson, K.D., Baird, A.H., Babcock, R.C., Beger, M., Bellwood, D.R., Berkelmans, R., Bridge, T.C. (2017a). Global warming and recurrent mass bleaching of corals. Nature, 543(7645), 373-377.

Hughes, T.P., Barnes, M.L., Bellwood, D.R., Cinner, J.E., Cumming, G.S., Jackson, J.B., Kleypas, J., van de Leemput, I.A., Lough, J.M., Morrison, T.H., Palumbi, S.R. (2017b). Coral reefs in the Anthropocene. Nature, 546(7656), 82-90.

Kroon, F.J. (2012). Towards ecologically relevant targets for river pollutant loads to the Great Barrier Reef. Marine Pollution Bulletin 65 (4-9), 261-266.

Kroon, F.J., Kuhnert, K.M., Henderson, B.L., Wilkinson, S.N., Kinsey-Henderson, A., Brodie, J.E., Turner, R.D.R. (2012). River loads of suspended solids, nitrogen, phosphorus and herbicides delivered to the Great Barrier Reef lagoon. Marine Pollution Bulletin 65, 167-181.

Petus, C.C., Collier, C.J., Devlin, M., Rasheed, M.A., McKenna, S. (2014). Using MODIS data for understanding changes in seagrass meadow health: a case study in the Great Barrier Reef (Australia). Marine Environmental Research 98, 68-85

Queensland and Australian Governments (2009). Reef Water Quality Protection Plan Secretariat, 2013. Reef Water Quality Protection Plan 2009: For the Great Barrier Reef World Heritage Area and Adjacent Catchments. Queensland Department of Premier and Cabinet, Brisbane.

Queensland and Australian Governments (2013). Reef Water Quality Protection Plan Secretariat, 2013. Reef Water Quality Protection Plan 2013: For the Great Barrier Reef World Heritage Area and Adjacent Catchments. Queensland Department of Premier and Cabinet, Brisbane.

Queensland and Australian Governments (2017). Draft Reef 2050 Water Quality Improvement Plan 20172022. Queensland Department of Premier and Cabinet, Brisbane. 40 pp.

Waterhouse, J. Brodie, J. Lewis, S. Mitchell. A. (2012). Quantifying the sources of pollutants to the Great Barrier Reef. Marine Pollution Bulletin 65, 394 - 406.

Waters, D.K., Carroll, C., Ellis, R., Hateley, L., McCloskey, G.L., Packett, R., Dougall, C., Fentie, B. (2014). Modelling reductions of pollutant loads due to improved management practices in the Great Barrier Reef catchments - Whole of GBR, Technical Report, Volume 1. Queensland Department of Natural Resources and Mines, Toowoomba, QLD, ISBN: 978-1-7423-0999. http://www.reefplan. qld.gov.au/measuringsuccess/paddock-to-reef/assets/Great-Barrier-Reef-Catchment-Modelling-Report.PDF

Wooldridge, S.A., Brodie, J.E., Kroon, F.J., Turner, R (2015). Ecologically relevant targets for dissolved inorganic nitrogen (DIN) discharge from the drainage basins of the Wet Tropics Region, Great Barrier Reef. Marine Pollution Bulletin. 97, 262 - 272 